\title{
L-band synthetic aperture radar (SAR) response to the tropical forest stands for carbon stock assessment
}

\begin{abstract}
Several attempts have been made to obtain forest stand parameters such as stand volume, stand density, basal area, biomass, and carbon stock from synthetic aperture radar (SAR) data. However the relationship between these parameters and radar backscatter has been a challenging issue since the last few years. In this study, L-band ALOS PALSAR satellite image with a spatial resolution of $12.5 \mathrm{~m}$ was utilized to identify the most ideal relationship between radar backscatter and aboveground carbon stock (ACS) atdifferent strata of tropical forest stands. The Forest Research Institute Malaysia (FRIM) campus which has about 420 ha of forest area was selected as the study area. Field survey was conducted in which ten (10) test plots $(50 \times 50 \mathrm{~m}, 0.25 \mathrm{ha})$ were established and all trees with the diameter at breast height (dbh) of $5 \mathrm{~cm}$ and above were inventoried. The calculated plot-based ACS was divided into six diameter classes - which is defined as strata - ofthe trees within the plot, which are i) $5 \mathrm{~cm}$ and above, ii) $10 \mathrm{~cm}$ and above, iii) $15 \mathrm{~cm}$ and above, iv) $20 \mathrm{~cm}$ and above, v) $25 \mathrm{~cm}$ and above, and vi) $30 \mathrm{~cm}$ and above. The total ACS of each class was correlated to the pixels of SAR backscatter corresponding to the plot location on the ground. Results showed that the forest was sensitive to the backscatter on horizontal-vertical polarized (HV) image as compared with horizontal-horizontal polarized $(\mathrm{HH})$ image and a combination of both $\mathrm{HH}$ and HV polarizations. However, only ACS that was calculated based on diameter class of 15 $\mathrm{cm}$ and above gave the strongest correlation to the SAR signal. The signals also tend to saturate when carbon stock starts to increase from 180 t hai 1 at around $\bar{i} 8 \mathrm{~dB}$. The experiment from the study suggested that only mature trees (i.e. of diameter more than 15 $\mathrm{cm}$ ) with sufficient canopy height can be included in inventory to obtain accurate carbon stock estimation when using satellite based L-band SAR data.
\end{abstract}

Keyword: Forest carbon; L-band radar; Satellite 